\title{
The Choice of Drainage Device in Complicated Glaucomas: Comparing Ahmed and Baerveldt Implants
}

\author{
MARILITA M. MOSCHOS ${ }^{1}$, EIRINI NITODA ${ }^{1}$, NIKOLAOS GOULIOPOULOS ${ }^{1}$, \\ CHRISTOS DAMASKOS ${ }^{2}$, KONSTANTINOS LAIOS ${ }^{1}$, ELENI BAGKLI ${ }^{3}$, \\ NIKOLAOS GARMPIS ${ }^{2}$ and GEORGE KITSOS ${ }^{3}$ \\ ${ }^{1}$ First Department of Ophthalmology, University of Athens Medical School, \\ G. Genimmatas General Hospital Athens, Athens, Greece; \\ ${ }^{2}$ Second Department of Propedeutic Surgery, Laiko General Hospital, \\ National and Kapodistrian University of Athens, Medical School, Athens, Greece; \\ ${ }^{3}$ Department of Ophthalmology, Medical School of University of Ioannina, Ioannina, Greece
}

\begin{abstract}
Background/Aim: Glaucoma is a chronic and progressive optic neuropathy which leads to deterioration of visual function. It is estimated to be the second leading cause of severe vision loss and blindness worldwide. Failure of antiglaucoma medication to sufficiently reduce intraocular pressure $(I O P)$ and poor compliance with medication are indications for glaucoma surgery, for example using glaucoma drainage devices. Our aim was to compare the surgical outcomes following the implantation of Ahmed FP7 and Baerveldt 350 drainage devices. Patients and Methods: Five hundred and fiftytwo patients with primary or secondary glaucoma were enrolled in the study. All patients had a history of failed trabeculectomy or other intraocular surgery, and $I O P \geq 18 \mathrm{~mm} \mathrm{Hg}$. The implantation of Ahmed (266 patients) or Baerveldt (286 patients) devices was randomly performed in the patients, who were subsequently examined for a period of 5 years. Follow-up visits were scheduled 1 day; 1 week; 1, 3 and 6 months; and 1, 1.5, 2, 3, 4 and 5 years postoperatively. Results: Significant reduction of IOP was achieved in both groups. Ahmed valve $(28.3 \pm 9.3,13.4 \pm 6.9,14.2 \pm 6$ and $12.7 \pm 4.5 \mathrm{mmHg}$ at baseline, 1,3 , and 5 years postoperatively, respectively) resulted in significantly greater IOP reduction compared to Baerveldt implant $(29.6 \pm 10.1,15.4 \pm 5.5,14.5 \pm 5.5$ and $14.7 \pm 4.4 \mathrm{mmHg}$ at baseline, 1,3 , and 5 years postoperatively, respectively). A significantly lower number of medications was required in the
\end{abstract}

This article is freely accessible online.

Correspondence to: Moschos M. Marilita, MD, Ph.D., Ikarias 6, Ekali, 14578 Athens, Greece. Mobile: +30 6944887319, Fax: +30 2107768321,e-mail: moschosmarilita@yahoo.fr

Key Words: Ahmed, Baerveldt, valve, implant, drainage, glaucoma.
Ahmed group in comparison to the Baerveldt one (Ahmed group: $1.5 \pm 1.4,1.4 \pm 1.5$ and 1.8 \pm 1.5 ; Baerveld group: $1.9 \pm 1.3$, $1.9 \pm 1.3$ and $2.2 \pm 1.4$, respectively). The incidence of treatment failure and the rate of glaucoma reoperation were significantly higher in the Baerveldt group (40\%) compared to the Ahmed group (17\%). Conclusion: Ahmed drainage implantation seemed to outclass that using the Baerveldt device in our study, in terms of efficacy and success rate.

Glaucoma is a chronic and progressive optic neuropathy characterized by the presence of enlarged optic disc cupping, neuroretinal rim loss, and thinning of the retinal nerve fiber layer, which leads to deterioration of visual function (1). It is estimated to be the second leading cause of severe vision loss and blindness worldwide, affecting approximately 80 million people, and accounting for $2.86 \%$ of the population over the age of 40 years by the year 2020 (2,3). In Europe, it is responsible for $20.5 \%$ cases of blindness, behind age-related macular degeneration (26\%) (4). The treatment of glaucoma aims to lower intraocular pressure (IOP), which is the main risk factor for the development of optic nerve damage. Anti-glaucoma drugs comprise the first-line therapy, including prostaglandin analogs, carbonic anhydrase inhibitors, beta-receptor antagonists, adrenergic agonists, and parasympathomimetics (5).

Failure of anti-glaucoma medication to sufficiently reduce IOP or poor compliance with the use of medication, are indications for glaucoma surgery. The latter involves trabeculectomy, nonpenetrating surgical procedures, including deep sclerectomy and viscocanalostomy, and implantation of glaucoma drainage devices (6). Drainage devices can lower IOP by promoting the movement of aqueous humor to an extrascleral reservoir through a small-caliber tube. The most common reasons to use such devices are neovascular glaucoma, followed by refractory glaucoma (no response to 
other glaucoma treatment), aphakic, and traumatic glaucoma (7). Two of the most commonly implanted aqueous drainage devices are the Ahmed and the Baerveldt valves, which impel aqueous humor to an episcleral plate, located in the equatorial region of the globe. The Ahmed glaucoma implant (New World Medical, Inc. Rancho Cucamonga, LA, USA) was approved by the United States Food and Drug Administration in 1993. It features a Venturi-based flow restrictor designed to manipulate postoperative hypotony and its complications. An IOP between 8 and $10 \mathrm{mmHg}$ boosts the opening of the valve, which finally reserves an IOP of $8 \mathrm{mmHg}$ or higher. The Baerveldt implant (BGI; Abbott Medical Optics, Abbott Park, IL, USA) is a nonvalve device that requires intraoperative mechanical flow restriction to allow adequate time for a bleb to form at the end plate $(8,9)$.

The choice of Ahmed or Baerveldt implant is frequently a dilemma for surgeons, who have to weigh the benefits and complications arising from the implantation of such devices. The purpose of our study was to compare the surgical outcomes of implantation of Ahmed and Baerveldt drainage devices.

\section{Patients and Methods}

Study design. This was a cross-sectional retrospective multicenter study, conducted at the Departments of Ophthalmology of the General Hospital G. Gennimatas (First Department of Ophthalmology, Medical School, National and Kapodistrian University of Athens, Greece) and of the University Hospital of Ioannina (Department of Ophthalmology, Medical School, University of Ioannina, Greece); and at other Ophthalmological Centers. Patients with refractory glaucoma and IOP $\geq 18 \mathrm{mmHg}$ were enrolled in the study. Cases of glaucoma involved patients with primary or secondary (neovascular or uveitic glaucoma, endothelialization syndrome) glaucoma who had undergone a failed trabeculectromy or other intraocular surgery. Ahmed or Baerveldt valve implantation was randomly performed in one eye of the enrolled patients, who were subsequently examined for a period of 5 years. Randomization was performed using a permuted block design, subsequent to patients' informed consent for participation in the study. The availability of each device also defined the choice of the implant. Ahmed FP7 and Baerveldt 350 implants were used. Since this was a surgical study and proper surgical informed consent was necessary, neither the patient nor the investigator could be masked to the randomization assignment. Follow-up visits were scheduled at 1 day; 1 week; 1,3 and 6 months; and 1, 1.5, 2, 3, 4 and 5 years postoperatively.

The implantation of the valves was performed by Dr. Marilita M. Moschos at the G. Gennimatas General Hospital, George Kitsos at the University Hospital of Ioannina and other eye surgeons and glaucoma specialists at their Ophthalmological Centers. Qualified and experienced surgeons were selected to perform the implantation of the valves, aiming to identify the differences in surgical outcomes and minimizing other confounding influences, such as surgical experience. The applied surgical procedures were based on those described by Barton and colleagues (10).

The study was performed in accordance to the tenets of the Declaration of Helsinki and the protocol used was approved by the Ethics Committee of our University Hospitals. Written informed consent was obtained from every participant. Power analysis was performed to justify the number of patients enrolled in the study.

Evaluated parameters. The ophthalmological examination performed during the follow-up visits included evaluation of the best corrected visual acuity based on Snellen chart, IOP measurement with Goldman applanation tonometry, slit-lamp examination, and fundoscopy. During the follow-up, the number of glaucoma medications used after surgery, reasons leading to treatment failure, incidence of reoperations, and reasons resulting in vision loss were also recorded. Surgical failure was defined as the presence of unregulated postoperative IOP (IOP $>18$ or $<5 \mathrm{mmHg}$ or not reduced by $20 \%$ from baseline), need for new glaucoma surgery, removal of the drainage device, and loss of light perception vision.

Statistical analysis. IBM SPSS Statistics 22.0 (IBM, Armonk, NY, USA) was used for the analysis. Descriptive analysis of all parameters, including IOP, number of glaucoma medications, reasons leading to treatment failure, incidence of reoperations, and reasons for vision loss was first carried out. Non-parametric Kolmogorov-Smirnov analysis was used to check the normal distribution of all variables. Possible differences in the prevalence of treatment failure and vision loss, as well as the incidence of reoperations between the two groups were estimated using the chisquared test. Independent samples $t$-test was applied to identify possible differences in IOP and the number of glaucoma medications between the two groups. A $p$-value of less than 0.05 was considered to be statistically significant.

\section{Results}

Patients. Five hundred and fifty-two patients (age range $=18$ 85 years) participated in this study and were classified into 282 patients with primary glaucoma (53\% male, mean age $=60 \pm 4$ years $)$ and 270 with secondary glaucoma $(54 \%$ males, mean age $=59 \pm 4$ years). The latter group included 160 patients with neovascular glaucoma and 36 with uveitic. The number of Ahmed or Baerveldt implants placed according to type of glaucoma is presented in Table I. The number of patients with neovascular or uveitic glaucoma, who received Ahmed or Baerveldt implants is also displayed in Table I.

Postoperative IOP values, medications and visual acuity. For both groups, the mean IOP at 1 and 5 years of follow-up was lower compared to the baseline values (Table II). Although mean preoperative IOP values did not differ significantly between the groups, at 1 and 5 years of follow-up, the values were significantly lower in the Ahmed group compared to the Baerveldt one (Table II). Postoperative reduction of IOP was achieved in both groups, using a lower number of medications than at baseline. The number of medications had to be slightly increased by the 5 th postoperative year compared to the $3 \mathrm{rd}$ year, but still remained lower than that at baseline (Table II). Moreover, the difference in the number of medications was significant between the Ahmed and Baerveldt groups only at the 3-year visit (Table II). There was a decrease in visual acuity by 2.5 Snellen lines in both groups at 5 years, which 
Table I. The distribution of Ahmed and Baerveldt implants according to the type of glaucoma.

\begin{tabular}{lccc}
\hline Type of glaucoma & Ahmed group, $\mathrm{n}$ & Baerveldt group, $\mathrm{n}$ & Overall, $\mathrm{n}$ \\
\hline Primary glaucoma with previous surgery & 144 & 138 & 282 \\
Secondary glaucoma & & & \\
$\quad$ Total & 142 & 128 & 270 \\
Neovascular & 82 & 18 & 160 \\
$\quad$ Uveitic & 22 & 266 & 36 \\
Total & 286 & 552 \\
\hline
\end{tabular}

was contributed to glaucoma, retinal diseases, corneal edema, and graft failure after keratoplasty (Table III).

Reasons for surgical failure in both groups and reoperation. The incidence of treatment failure was greater in the Baerveldt group (114 cases) compared to the Ahmed one (94 cases). The reasons for surgical failure included inadequate IOP control without additional glaucoma surgery, explantation due to complications, persistent hypotony, loss of light perception vision, and reoperation to lower IOP (Table IV). The frequency of persistent hypotony was tenfold in the Ahmed group in comparison to the Baerveldt one, whereas the loss of light perception was observed in almost double the number of patients with the Ahmed implant compared to the Baerveldt one (Table IV). On the other hand, patients with a Baerveldt valve underwent a new anti-glaucomatous procedure almost twice as frequently as those in the Ahmed group (Table IV).

The 5-year cumulative Kaplan-Meier percentage of reoperation for glaucoma was estimated to be $17.2 \pm 2.6 \%$ (20 cases) and $41.6 \pm 3.7 \%$ (52 cases), in the Ahmed and Baerveldt groups, respectively. The recorded type of reoperation included an additional tube shunt (16 out of 286 cases in the Ahmed group and 26 out of 266 cases in the Baerveldt group), cyclodestructive procedures (four out of 286 cases in the Ahmed group and 24 out of 266 cases in the Baerveldt group) and tube revision followed by cyclodestructive procedures (no cases out of 286 in Ahmed group and two cases out of 266 in the Baerveldt group).

\section{Discussion}

In our study, we noted that both glaucoma drainage devices successfully significantly reduced the IOP in all patients. Furthermore, the mean IOP was found to be significantly lower in the Ahmed group at 1- and 5-years follow-up. The IOP was postoperatively controlled using a lower number of medications in both groups, although this number was significantly lower in patients with an Ahmed implant at 3 -year follow-up. A decrease in visual acuity by 2.5 Snellen lines was observed in both groups at 5 years. The incidence of treatment failure was greater in the Baerveldt group
Table II. Intraocular pressure (IOP) (mean \pm standard deviation) and numbers of medications in the Ahmed and Baerveldt groups.

\begin{tabular}{lccc}
\hline Timepoint & $\begin{array}{c}\text { Ahmed } \\
\text { group }\end{array}$ & $\begin{array}{c}\text { Baerveldt } \\
\text { group }\end{array}$ & $p$-Value \\
\hline Baseline & & & \\
$\quad$ Number of patients & 286 & 266 & \\
IOP, mmHg & $28.3 \pm 9.3$ & $29.6 \pm 10.1$ & 0.71 \\
$\quad$ Glaucoma medications, $\mathrm{n}$ & $3.5 \pm 1.1$ & $3.4 \pm 1.1$ & 0.34 \\
1 Year FU & & & \\
$\quad$ Number of patients & 134 & 266 & \\
IOP, mmHg & $13.4 \pm 6.9$ & $15.4 \pm 5.5$ & 0.018 \\
$\quad$ Glaucoma medications, $\mathrm{n}$ & $1.5 \pm 1.4$ & $1.9 \pm 1.3$ & 0.078 \\
3 Years FU & & & \\
$\quad$ Number of patients & 200 & 212 & \\
IOP, mmHg & $14.2 \pm 6$ & $14.5 \pm 5.5$ & 0.078 \\
$\quad$ Glaucoma medications, $\mathrm{n}$ & $1.4 \pm 1.5$ & $1.9 \pm 1.3$ & 0.018 \\
5 Years FU & & & \\
$\quad$ Number of patients & 174 & 174 & \\
IOP, mmHg & $12.7 \pm 4.5$ & $14.7 \pm 4.4$ & 0.012 \\
Glaucoma medications, $\mathrm{n}$ & $1.8 \pm 1.5$ & $2.2 \pm 1.4$ & 0.28 \\
\hline
\end{tabular}

FU: Follow-up.

compared to the Ahmed one. A higher number of reoperations was recorded in patients with a Baerveldt implant, whereas patients in the Ahmed group more frequently exhibited persistent hypotony and loss of light perception.

The surgical outcomes of drainage devices have been demonstrated by the Tube versus Trabeculectomy study, which included 107 patients who underwent Baerveldt implantation and 105 patients who underwent trabeculectomy with mitomycin. The baseline IOP exhibited no statistically significant differences between the two groups, irrespective of previous trabeculectomy, cataract extraction with intraocular lens implantation, or both. No significant differences were found in the mean IOP, number of medications, proportion of patients who lost more than two lines of Snellen visual acuity and the rate of late postoperative complications at 5 years of follow-up. The most frequent cause of vision loss was the progression of glaucomatous disease in both groups. However, the incidences of surgical failure, early postoperative complications and re-operation were higher in patients who underwent trabeculectomy (11). Furthermore, 
Table III. Prevalence of reasons contributing to vision loss.

\begin{tabular}{lcc}
\hline Cause & $\begin{array}{c}\text { Ahmed } \\
\text { group, n (\%) }\end{array}$ & $\begin{array}{c}\text { Baerveldt } \\
\text { group, n (\%) }\end{array}$ \\
\hline Loss of >2.5 Snellen lines at 5 years & $76(44 \%)$ & $72(42 \%)$ \\
Glaucoma/retinal disease & $34(45 \%)$ & $28(39 \%)$ \\
Corneal edema & $10(13 \%)$ & $20(28 \%)$ \\
Graft failure & $20(26 \%)$ & $6(8 \%)$ \\
Cataract & $6(8 \%)$ & $6(8 \%)$ \\
Other & $10(13 \%)$ & $2(3 \%)$ \\
Unknown & $4(5 \%)$ & $10(14 \%)$ \\
\hline
\end{tabular}

Hamanaka et al. supported the notion that glaucoma drainage implant surgery combined with trabeculectomy using nonabsorbable tube was an excellent approach for any type of glaucoma in Japanese patients (12).

The implantation of an Ahmed drainage device was related to high success rate $(69 \%)$ by Zarei et al. and our results are consistent with this finding. They found that the IOP decreased from a mean preoperative value of $30.8 \pm 5.6 \mathrm{mmHg}$ to $20.0 \pm 6.4$ $\mathrm{mmHg}$, along with a reduction in medication from $3.7 \pm 0.4$ preoperatively to $2.5 \pm 1.1$ postoperatively. The estimated prevalence of postoperative complications was $57.1 \%$ (13). Zhu et al. also demonstrated reduction of IOP after Ahmed valve implantation in 79 eyes with refractory glaucoma. They found significant reduction in the mean IOP from 39.9 \pm 12.6 $\mathrm{mmHg}$ preoperatively to $19.3 \pm 9.6 \mathrm{mmHg}$ at the final followup (14). Dave et al. revealed that the IOP was reduced by 14.4 $\mathrm{mm} \mathrm{Hg}$ in 11 patients who underwent Ahmed valve implantation. Furthermore, these patients used a significantly lower number of medications postoperatively (1.6 vs. 2.6 preoperatively), as our patients did. The referred complications included shallow anterior chamber with choroidal detachment at 1 week, which resolved spontaneously with medications, tube corneal touch and tube retraction (15).

Tsai et al. performed a retrospective study to compare the surgical outcome of Baerveldt and Ahmed shunt implants, recruiting 118 patients with refractory glaucoma. They noted, as we did, that the success rate (defined as $6 \mathrm{mmHg} \leq \mathrm{IOP} \leq 21$ $\mathrm{mmHg}$ without additional glaucoma surgery or devastating complication) in the Ahmed group (48 patients) was higher than in the Baerveldt one (70 patients) during a follow-up of 12 months. In particular, they observed that IOP was lower in patients with the Ahmed implant at 1 day and 1 week postoperatively, and these patients received fewer medications at 1 week and 1 month $(p<0.001)$ after surgery $(16)$. We found that the difference in mean IOP between the Ahmed and Baerveldt groups was statistically significant at 1 and 5 years, whereas the difference in the number of medications was significant only at the 3-year visit. On the other hand, Syed $e t$ $a l$. identified no statistically significant differences in IOP
Table IV. Reasons for treatment failure in Ahmed and Baerveldt groups.

\begin{tabular}{lcc}
\hline Reason & $\begin{array}{c}\text { Ahmed } \\
\text { group, n (\%) }\end{array}$ & $\begin{array}{c}\text { Baerveldt } \\
\text { group, n (\%) }\end{array}$ \\
\hline $\begin{array}{l}\text { Inadequate IOP control without } \\
\text { additional glaucoma surgery }\end{array}$ & $34(36 \%)$ & $46(40 \%)$ \\
Reoperation to lower IOP & $16(17 \%)$ & $46(40 \%)$ \\
Explantation due to complications & $8(8 \%)$ & $6(5 \%)$ \\
Persistent hypotony & $12(13 \%)$ & $2(2 \%)$ \\
Loss of light perception & $24(26 \%)$ & $14(12 \%)$ \\
Total & $94(33 \%)$ & $114(43 \%)$ \\
\hline
\end{tabular}

IOP: Intraocular pressure.

control and postoperative complications comparing 32 patients with Baerveldt implant and 32 patients with Ahmed valve (17).

The Ahmed Baerveldt Comparison (ABC) study compared the long-term outcomes and complications between 133 patients with Baerveldt (model 101-350) implant and 143 patients with Ahmed (model FP7) device at 16 clinical centers worldwide. The two groups exhibited no statistically significant differences in visual acuity, IOP, central corneal thickness, number of glaucoma medications, and previous interventions (such as cataract surgery, laser, and trabeculectomy) at baseline. Moreover, the incidence of primary open angle or angle closure glaucoma, and neovascular and uveitic glaucomas were similar between the two groups. The percentages of intraoperative complications, including hyphema and scleral perforation were also similar (10). Studying a larger number of patients, we noted that persistent hypotony was 10-fold more frequent in the Ahmed group compared to the Baerveldt one, whereas the loss of light perception was observed in almost double the number of patients with the Ahmed implant compared to the Baerveldt one.

In the ABC study, successful outcome (defined as $6 \mathrm{~mm}$ $\mathrm{Hg} \leq \mathrm{IOP} \leq 21 \mathrm{~mm} \mathrm{Hg}$, no reoperation for glaucoma or removal of implant, maintenance of vision) did not appear to differ significantly comparing the Ahmed and Baerveldt groups (14\% and $16.4 \%$, respectively) at 1 -year follow up. At 1 year, treatment failure had occurred in 16\% of patients with Ahmed valve and in $14 \%$ of patients with the Baerveldt device (1820). Treatment failure was observed in $33 \%$ and $43 \%$ of patients with Ahmed and Baerveldt valve, respectively, in our study. The reasons for failure in the ABC study included inadequately controlled IOP without additional glaucoma surgery, reoperation for glaucoma, persistent hypotony, and loss of light perception. These complications are similar to those of our study. In the ABC study, a statistically significant decrease in IOP was detected in both groups at 1, 3 and 5 years of follow-up. However, the mean IOP in the Baerveldt group was approximately 1 to $2 \mathrm{mmHg}$ lower than that of the Ahmed group at 1 and 3 months, and at 1, 1.5, 4 and 5 years. No statistically significant decrease in IOP was noted between the two groups at 6-month, and 2- and 3-year follow-up visits 
(18-20). In our study, IOP was significantly different between the two groups at 1 and 5 years.

Postoperative visual acuity did not show any statistically significant difference between the two groups in the $A B C$ study, although vision was significantly reduced for both groups at 1, 3 and 5 years of follow-up after the implantation of drainage devices. The most frequent causes of vision loss during the first year of the study were glaucoma, macular disease, and cataract. Corneal edema, retinal detachment, diabetic retinopathy, endophthalmitis, and posterior capsular opacification were less common reasons for vision loss (1820). Our findings were consistent with those of the ABC study.

Seven percent of the patients in the Ahmed group and 14\% in the Baerveldt group of the ABC study underwent some kind of intervention, including anterior chamber reformation, bevacizumab injection (patients with neovascular glaucoma), laser revision of bleb and needling at the slit lamp, during the 1 -year follow-up. The incidence of reoperations at 1-year follow-up was $8 \%$ and $1 \%$ in Ahmed group and Baerveldt group, respectively. In our study, $17 \%$ and $40 \%$ of patients with Ahmed and Baerveldt implants, respectively, underwent an anti-glaucomatous reoperation. Although the mean number of medications was lower in the Baerveldt group compared to the Ahmed one, this difference was statistically significant only at 2, 3, and 4 years of follow-up (18-20). In contrast, we found that the number of medications differed significantly between the two groups only at the 3-year visit.

Furthermore, the ABC study noted that the incidence of early postoperative complications was higher in Baerveldt group (58\%) compared to the Ahmed one (43\%), especially cases of tube occlusion ( $9 \%$ versus $2 \%$ in Ahmed group) at 1year follow-up. The number of reoperations concerning complications was significantly greater in patients with a Baerveldt implant (at 1 year: $13 \%$ vs. $5 \%$; at 3 years: $20 \% v s$. $1 \%)$. The reasons for reoperation included clearing of an occluded tube $(19,20)$, conjunctival repair for leak or tube erosion, replacement of patch graft, implant removal secondary to diplopia or to Propionibacterium acnes endophthalmitis, and drainage of suprachoroidal hemorrhage (18-20).

The Ahmed versus Baerveldt study compared Ahmed (model FP7) and Baerveldt (model 350) implants and was performed at seven international clinical sites, involving 10 surgeons between 2005 and 2009 (21). The percentage of failure at 1 year was $43 \%$ and $28 \%$ in the Ahmed and Baerveldt groups, respectively. The most common reason for failure in both groups at 1 year was inadequate IOP control, followed by additional glaucoma surgery required, devastating complications, and loss of light perception (22). After 3 years of follow-up, failure had occurred in $51 \%$ and $39 \%$ of the patients in the Ahmed and Baerveldt groups, respectively. In our study, failure rates in the Ahmed and Baerveldt group were $33 \%$ and $43 \%$, respectively, at the 5 -year visit. Elevated IOP was the most common reason for failure in both groups during the 3 years (9). The number of medications required in the Ahmed group (1.6 \pm 1.2$)$ was significantly higher than in the Baerveldt group (1.3 \pm 1.2$)(21)$. No differences in visual acuity or postoperative complications were detected between the two devices after 1 year of follow-up (22). The prevalence of complications was similar in both groups at the 3-year visit (52\% in both groups, including the aforementioned of the first year) (9).

Wang et al. observed that patients with a Baerveldt implant had better postoperative control of IOP, using fewer medications. On the other hand, use of the Ahmed valve implantation was followed by lower incidence of total and severe complications (23). A retrospective study was conducted by El Gendy and Song to evaluate the outcomes and complications following Baerveldt (model BG 101-350) and Ahmed (model S-2) valve implantation in children (under 18 years old). In Baerveldt, the success rate was estimated to be $80 \%$, whereas in the Ahmed group it was $54.5 \%$. The mean postoperative IOP was found to be 19.6 and $24 \mathrm{mmHg}$, respectively. They concluded that the Baerveldt implant is more efficient in controling IOP in pediatric glaucoma (24).

The limitation of our study is that the outcomes concern only these models of Baerveldt and Ahmed implants and they cannot be extrapolated to different models or other types of drainage devices. Patients were excluded if other ocular procedures were required in conjunction with glaucoma surgery, so the study does not provide information about the preferred implant when concurrent ocular surgery is needed.

\section{Conclusion}

We concluded that Ahmed implantation produced greater IOP reduction, also using a lower number of medications. Moreover, the incidence of treatment failure and rate of glaucoma reoperation was lower in the Ahmed group compared to the Baerveldt one during the 5 years of followup. Efficient surgical treatment of glaucoma is very important in order to avoid irreversible damage of the optic nerve and loss of visual field in the older population.

\section{Conflicts of Interest}

The Authors report no conflicts of interest in regard to this work. No funding or sponsorship was received for this study or publication of this article. All Authors had full access to all of the data in this study and take complete responsibility for the integrity of the data and accuracy of the data analysis.

\section{Authors' Contributions}

MMM performed surgeries, and wrote and revised the manuscript. NG revised the manuscript and performed the statistical analysis. $\mathrm{CD}$ and NG performed the statistical analysis. EN and KL collected data. KG recruited patients and revised the manuscript. EB critically corrected and revised the manuscript. 


\section{Acknowledgements}

All the Authors would like to express their gratitude to the eye surgeons and glaucoma specialists who provided their data: Ioannis K. Lamprinakis, Former Chief of Ophthalmology Department, Evaggelismos General Hospital of Athens, Aikaterini Karathanou, Consultant Ophthalmic Surgeon, University of Thessaly, Anastasia Nikolopoulou, Private Ophthalmic Surgeon, Volos, and Professor George Baerveldt, Department of Ophthalmology, University of California, Irvine.

\section{References}

1 Chiu SL, Chu CL, Muo CH, Chen CL and Lan SJ: The prevalence and the incidence of diagnosed open-angle glaucoma and diagnosed angle-closure glaucoma: Changes from 2001 to 2010. J Glaucoma 25: e514-519, 2016. PMID: 26900828. DOI: 10.1097/IJG.0000000000000381

2 Resnikoff S, Pascolini D, Etya'ale D, Kocur I, Pararajasegaram R, Pokharel GP and Mariotti SP: Global data on visual impairment in the year 2002. Bull World Health Organ 82: 844851, 2004. PMID: 15640920. DOI: /S0042-96862004001100009

3 Quigley HA and Broman AT: The number of people with glaucoma worldwide in 2010 and 2020. Br J Ophthalmol 90: 262267, 2006. PMID: 16488940. DOI: 10.1136/bjo.2005.081224

4 Prokofyeva E and Zrenner E: Epidemiology of major eye diseases leading to blindness in Europe: A literature review. Ophthalmic Res 47: 171-188, 2012. PMID: 22123077. DOI: 10.1159/000329603

5 Schmidl D, Schmetterer L, Garhöfer G and Popa-Cherecheanu A: Pharmacotherapy of glaucoma. J Ocul Pharmacol Ther 31: 63-77, 2015. PMID: 25587905. DOI: 10.1089/jop.2014.0067

6 Sharaawy T and Bhartiya S: Surgical management of glaucoma: evolving paradigms. Indian J Ophthalmol 59(Suppl): S123-130, 2011. PMID: 21150024. DOI: 10.4103/0301-4738.73692

7 Montañez FJ, Laso E, Suñer M and Amaya C: Ahmed drainage device implant. Our experience between 1995 and 2003. Arch Soc Esp Oftalmol 80: 239-244, 2005 (in Spanish). PMID: 15852165.

8 Lee JJ, Park KH, Kim DM and Kim TW: Clinical outcomes of Ahmed glaucoma valve implantation using tube ligation and removable external stents. Korean J Ophthalmol 23: 86-92, 2009. PMID: 19568356. DOI: 10.3341/kjo.2009.23.2.86

9 Christakis PG, Tsai JC, Kalenak JW, Zurakowski D, Cantor LB, Kammer JA and Ahmed II: The Ahmed versus Baerveldt study: Three-year treatment outcomes. Ophthalmology 120: 2232-2240, 2013. PMID: 23796764. DOI: 10.1016/j.ophtha.2013.04.018

10 Barton K, Gedde SJ, Budenz DL, Feuer WJ, Schiffman J and Ahmed Baerveldt Comparison Study Group: The Ahmed Baerveldt comparison study methodology, baseline patient characteristics, and intraoperative complications. Ophthalmology 118: 435-442, 2011. PMID: 20932581. DOI: 10.1016/j.ophtha.2010.07.015

11 Gedde SJ, Schiffman JC and Feuer WJ: The tube versus trabeculectomy study: Design and baseline characteristics of study patients. Am J Ophthalmol 140: 275-287, 2005. PMID: 16086949. DOI: 10.1016/j.ajo.2005.03.031

12 Hamanaka T, Otora K, Ono K and Ishida N: Long-term results of non-valved glaucoma drainage implant surgery and glaucoma drainage implant combined with trabeculectomy. Indian J Ophthalmol 62: 911-916, 2014. PMID: 25370391. DOI: $10.4103 / 0301-4738.143926$
13 Zarei R, Amini H, Daneshvar R, Nabi FN, Moghimi S, Fakhraee G, Eslami Y, Mohammadi M and Amini N: Long-term outcomes of Ahmed glaucoma valve implantation in refractory glaucoma at Farabi Eye Hospital, Tehran, Iran. Middle East Afr J Ophthalmol 23: 104-109, 2016. PMID: 26957848. DOI: 10.4103/0974-9233.164611

14 Zhu Y, Wei Y, Yang X, Deng S, Li Z, Li F and Zhuo Y: Clinical Outcomes of FP-7/8 Ahmed glaucoma valves in the management of refractory glaucoma in the Mainland Chinese population. PLoS One 10: e0127658, 2015. PMID: 25996991. DOI: 10.1371/journal.pone. 0127658

15 Dave P, Senthil S, Choudhari N and Sekhar GC: Outcomes of Ahmed valve implant following a failed initial trabeculotomy and trabeculectomy in refractory primary congenital glaucoma. Middle East Afr J Ophthalmol 22: 64-68, 2015. PMID: 25624676. DOI: 10.4103/0974-9233.148351

16 Tsai JC, Johnson CC and Dietrich MS: The Ahmed shunt versus the Baerveldt shunt for refractory glaucoma: A single-surgeon comparison of outcome. Ophthalmology 110: 1814-1821, 2003. PMID: 13129882. DOI: 10.1016/S0161-6420(03)00574-8

17 Syed HM, Law SK, Nam SH, Li G, Caprioli J and Coleman A: Baerveldt-350 implant versus Ahmed valve for refractory glaucoma: A case-controlled comparison. J Glaucoma 13: 38-45, 2004. PMID: 14704542.

18 Budenz DL, Barton K, Feuer WJ, Schiffman J, Costa VP, Godfrey DG, Buys Y and Ahmed Baerveldt Comparison Study Group: Treatment outcomes in the Ahmed Baerveldt. Comparison study after 1 year of follow-up. Ophthalmology 118: 443-452, 2011. PMID: 20932583. DOI: 10.1016/j.ophtha.2010.07.016

19 Barton K, Feuer WJ, Budenz DL, Schiffman J, Costa VP, Godfrey DG, Buys YM and Ahmed Baerveldt Comparison Study Group: Three-year treatment outcomes in the Ahmed Baerveldt comparison study. Ophthalmology 121: 1547-1557, 2014. PMID: 24768240. DOI: 10.1016/j.ophtha.2014.01.036

20 Budenz DL, Feuer WJ, Barton K, Schiffman J, Costa VP, Godfrey DG, Buys YM and Ahmed Baerveldt Comparison Study Group: Postoperative complications in the Ahmed Baerveldt comparison study during five years of follow-up. Am J Ophthalmol 163: 7582.e3, 2016. PMID: 26596400. DOI: 10.1016/j.ajo.2015.11.023

21 Christakis PG, Tsai JC, Zurakowski D, Kalenak JW, Cantor LB and Ahmed II: The Ahmed Versus Baerveldt study: Design, baseline patient characteristics, and intraoperative complications. Ophthalmology 118: 2172-2179, 2011. PMID: 21906813. DOI: 10.1016/j.ophtha.2011.05.003

22 Christakis PG, Kalenak JW, Zurakowski D, Tsai JC, Kammer JA, Harasymowycz PJ and Ahmed II: The Ahmed Versus Baerveldt study: One-year treatment outcomes. Ophthalmology 118: 21802189, 2011. PMID: 21889801. DOI: 10.1016/j.ophtha.2011.05.004

23 Wang YW, Wang PB, Zeng C and Xia XB: Comparison of the Ahmed glaucoma valve with the Baerveldt glaucoma implant: A meta-analysis. BMC Ophthalmol 15: 132, 2015. PMID: 26463843. DOI: 10.1186/s12886-015-0115-y

24 El Gendy NM and Song JC: Long term comparison between single-stage Baerveldt and Ahmed glaucoma implants in pediatric glaucoma. Saudi J Ophthalmol 26: 323-326, 2012. PMID: 23961013. DOI: 10.1016/j.sjopt.2012.06.003

Received December 28, 2018

Revised March 12, 2019

Accepted March 18, 2019 